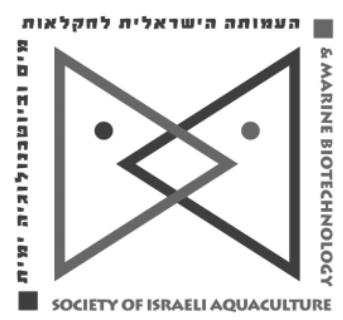

The IJA appears exclusively as a peer-reviewed on-line open-access journal at http://www.siamb.org.il/. To read papers free of charge, please register online at registration form.

Sale of $I J A$ papers is strictly forbidden.

\title{
Intestinal Fatty Acid Binding Protein Gene (I-FABP) in Golden Pompano Trachinotus ovatus (Linnaeus 1758) Larvae: Ontogenetic Expression and Response to Water Temperature and Nutrition Manipulation
}

\author{
Maoshang Lin ${ }^{1,3}$, Xianming Tang ${ }^{2}$, Jian G. Qin ${ }^{4}$, Zhenhua Ma ${ }^{3, *}$, Wei Wang ${ }^{1, * *}$, \\ ${ }^{1}$ College of Fisheries and Life Sciences, Dalian Ocean University, Dalian 116023, China \\ ${ }^{2}$ Hainan Academy of Ocean and Fisheries Sciences, Haikou, 570203 \\ 3 Tropical Aquaculture Research and Development Center, South China Sea Fisheries \\ Research Institute, Chinese Academy of Fishery Sciences, Sanya 572018, China \\ 4 School of Biological Sciences, Flinders University, GPO Box 2100, Adelaide, SA 5001, \\ Australia
}

\begin{abstract}
The gene for fatty acid binding proteins (I-FABP) in golden pompano Trachinotus ovatus larvae was cloned and analyzed from hatch to 18 dayspost hatch (DPH). The I-FABP gene (GenBank accession: MF034871) of golden pompano is composed of 815 bp with an open reading frame of 399 $\mathrm{bp}$, encoded in one amino acid with a molecular weight of $15.24 \mathrm{kDa}$. The predicted amino acid sequence of I-FABP genes from golden pompano showed high similarity and identity with Japanese sea bass Lateolabrax japonicus (97\% and $87.9 \%$, AOW69620.1). The highest tissue expression of I-FABP genes was found in the intestine, followed by the eye on $18 \mathrm{DPH}$. During the ontogenetic development, the expression of I-FABP genes remained at a low level during the first five days, and reached the highest level on 12 and 18 $\mathrm{DPH}$. The expression of I-FABP genes was not significantly affected by environmental temperature on $12 \mathrm{DPH}$, but was significantly affected by the temperature on $18 \mathrm{DPH}$. Nutrition enhancement with algae containing high fatty acids significantly affected the expression of I-FABP genes. The highest expression was observed in the non-enriched treatment, but the lowest expression was in the Nannochloropsis feeding treatment. Results of the present study indicate that the expression of the I-FABP gene varies with environmental temperature and nutritional conditions during the ontogenetic development of golden pompano larvae. The expression of I-FABP genes may be potentially used as an indicator for assessing nutrient supply and functional development of the digestive system in fish larvae.
\end{abstract}

\footnotetext{
* Corresponding author 1 . Tel: +86 0898-83361232, fax: +86 020-84451442, e-mail: zhenhua.ma@hotmail.com

Corresponding author 2. e-mail: wangwei@dlou.edu.cn
} 
Lin et al.

\section{Introduction}

Fatty acid binding proteins (FABPs) belong to a multi-gene family of 14-16 kDa molecular mass and bind long chain fatty acids in both vertebrates and invertebrates (Alvite et al., 2008; Borchers et al., 1989; Kanda et al., 1989). The length of FABPs varies from 126 to 137 amino acids depending on species (Chen and Shi, 2009; Pelsers et al., 2005; Sharma et al., 2004). FABPs can mediate the transportation of free fatty acids for targeting specific metabolic pathways, protecting cells from cytotoxic effects of free fatty acids, modifying lipid metabolic enzymes, and participating in fatty acid signaling within the nucleus (Besnard et al., 2002; Lowe et al., 1987; Storch and McDermott, 2009). Different FABP types have been named after the mammalian tissue from which they were first isolated, such as intestine, heart, liver, myelin, and adipose tissues. Early studies have confirmed that the existence of these FABP types fulfilled specific roles associated with the histological structure and physiological functions of different tissues (Banaszak et al., 1994; Veerkamp et al., 1991; Veerkamp et al., 1993).

The intestinal fatty acid-binding protein (I-FABP) is a small cytosolic protein and has been considered to play a crucial role in intracellular fatty acid trafficking and metabolism in fish gut (Her et al., 2004). Evidence has indicated that the expression of IFABP genes is an important marker for intestinal differentiation in humans (Sonnino et al., 2000), rats (Likic and Prendergast, 1999), frogs (Chalmers et al., 2000), and fish (Pierce et al., 2000). The expression levels of I-FABP genes may be related to the status of tissue damage and regeneration (Schroyen et al., 2012; Simula et al., 2010). In commercially cultured fish, the I-FABP has been selected as a marker to investigate physiological function and response to the nutrition change in fish diets (Overland et al., 2009; Venold et al., 2013; Yamamoto et al., 2007), but its role in fish larvae is largely unknown.

Golden pompano belongs to the family of Carangidae and is a good candidate species for aquaculture owing to fast growth and suitability for cage culture (Ma et al., 2014). Although artificial breeding and culture of this species have made substantial progress, the poor quality of juvenile fish is a major issue hindering further expansion of production of this species in hatcheries (Ma et al., 2016b; Zheng et al., 2016). The understanding of the ontogeny of the digestive system and nutritional requirement of fish larvae may improve management of fish feeding and fingerling quality in the hatchery production system. This study aims to quantify the expression of I-FABP genes at different water temperatures and feed types in golden pompano larvae from hatching to the formation of a functional stomach. The expression pattern of I-FABP genes could provide essential information to assess the functional change of the digestive system of golden pompano larvae during early ontogeny. In addition, the expression level of I-FABP genes may be used as a potential indicator to predict nutrient malformation of fish larvae in aquaculture.

\section{Materials and methods}

Larval rearing of golden pompano. The fish specimens in this study were obtained from a previous feeding trial in our laboratory ( $\mathrm{Ma}$ et al., 2016a) in which fertilized eggs of golden pompano hatched in $500 \mathrm{~L}$ fiberglass incubators at $26.5^{\circ} \mathrm{C}$. On $2 \mathrm{DPH}$, larvae were stocked into three $1000 \mathrm{~L}$ larval rearing tanks, supplied with upwelling filtered seawater ( $5-\mu \mathrm{m}$ pore size) from the bottom of each tank and a daily exchange rate of $200 \%$. Two air stones were used in each tank to maintain dissolved oxygen close to saturation. Light intensity was maintained at 2400 lux. The light regime was set at $14 \mathrm{~h}$ light and $10 \mathrm{~h}$ dark. Salinity was maintained at $33 \pm 0.8 \%$, and water temperature was $26.5 \pm 1.0^{\circ} \mathrm{C}$ throughout the experiment. Rotifers (Brachionus rotundiformis) were fed to fish larvae from $2 \mathrm{DPH}$ to $10 \mathrm{DPH}$ at a density of $10-20 \mathrm{ind} / \mathrm{mL}$. Artemia nauplii were added into the rearing tank from $10 \mathrm{DPH}$ until completion of the experiment. Both rotifers and Artemia nauplii were enriched with DHA Protein Selco (INVE Aquaculture, Salt Lake City, USA) according to the manufacturer's instructions.

Response of I-FABP gene to rearing temperature. Upon arrival, all eggs were transferred into $500 \mathrm{~L}$ incubators and hatched at $26^{\circ} \mathrm{C}$. The experimental conditions included three constant temperatures, 23,26 , and $29^{\circ} \mathrm{C}$ with three replicates each. On 2 $\mathrm{DPH}$, yolk sac larvae were acclimatized at each of these temperatures for $5 \mathrm{~h}$, and 
stocked in $500 \mathrm{~L}$ fiberglass tanks at a density of $60 \mathrm{fish} / \mathrm{L}$. Apart from the different rearing temperatures, all feeding protocols and rearing conditions were the same as described above.

Response of I-FABP gene to nutrition manipulation. The current experiment included three dietary treatments with three replicates each. Artemia nauplii were nutritionally used in three ways: (1) enriched with instant microalgal paste (Nannochloropsis sp., Qingdao Hong Bang Biological Technology Co., Ltd, Qingdao, China); (2) enriched with Algamac 3080 \& (Aquafauna, USA); and (3) with no enrichment as control. In the experimental diet, the Nannochloropsis enriched diet contained the highest content of polyunsaturated fatty acids ( $49.63 \pm 3.78 \%$ of total fatty acids), while the lowest one was observed in the non-enriched diet (40.64 $\pm 4.39 \%$ of total fatty acids) (Yang et al., 2015).

Total RNA extraction and reverse transcription. On $0,1,2,3,4,5,12$, and 18 DPH, approximately $300 \mathrm{mg}$ (wet weight) fish larvae were sampled from rearing tanks in triplicate. Approximately 50 individuals were collected on $12 \mathrm{DPH}$ and $18 \mathrm{DPH}$ to assess the effects of temperature and nutrition manipulation. On $18 \mathrm{DPH}$, a total of 100 individuals were collected and examined under a dissecting microscope for the analysis of gene expression in tissues. Total RNA was extracted using TRIzol (Invitrogen, USA). RNA integrity was verified by electrophoresis on a formaldehyde-agarose gel (1.2\%). The RNA concentration was measured by absorbance at $260 \mathrm{~nm}$ and the purity was determined at the ratio of absorbance between $260 \mathrm{~nm}$ and $280 \mathrm{~nm}(260 / 280)$. RNA was reversetranscribed to cDNA with oligo (dT) primers using a PrimeScript first strand CDNA synthesis kit (TaKaRa Biotechnology, Dalian Co., Ltd). The cDNA was used as a template in subsequent PCR.

Cloning of the gene CDNA and real-time PCR. Based on a preliminary study on golden pompano transcriptome sequences in our laboratory (Illumina HiSeq2000, annotated by NR, KOG, kegg, and Swissprot), the primers for genes cloning were designed with Primer 5.0 (Premier Biosoft International, Palo Alto, CA, USA) (Table 1). The PCR reaction systems included $1 \mu \mathrm{L}$ of golden pompano larval CDNA, $1 \mu \mathrm{L}$ of gene-specific forward primer $(F), 1 \mu \mathrm{L}$ of gene-specific reverse primer (R), $0.5 \mu \mathrm{L}$ of ExTaq, $5 \mu \mathrm{L}$ of PCR buffer, $4 \mu \mathrm{L}$ of dNTP mixture $(2.5 \mu \mathrm{M})$ and $37.5 \mu \mathrm{L}$ of $\mathrm{dddH}_{2} \mathrm{O}$, adding up to a total volume of 50 $\mu \mathrm{L}$. The PCR conditions were denaturation at $94^{\circ} \mathrm{C}$ for $1 \mathrm{~min}, 35$-cycles of $94^{\circ} \mathrm{C}$ for $30 \mathrm{~s}$, annealing temperature of each gene for $30 \mathrm{~s}, 72^{\circ} \mathrm{C}$ for $4 \mathrm{~min}$, followed by a $10 \mathrm{~min}$ extension at $72^{\circ} \mathrm{C}$. The PCR products were cloned into the PMD-19T vector (TAKARA, Japan), and then sequenced.

Table 1 Sequences of primers used in this study.

\begin{tabular}{llc}
\hline Primers & Sequence $\left(5^{\prime}-3^{\prime}\right)$ & $\begin{array}{l}\text { Amplicon sizes } \\
(b p)\end{array}$ \\
\hline I-FABP -F & GGCATGGCACAGTTCTT & 689 \\
I-FABP -R & CACTTTTCACAGGTTATTAGGT & 111 \\
I-FABP- qF & CGGCTCCTGGAAATTGATC & 101 \\
I-FABP- qR & ATGGTTATCTTGAGGTTGTCGTG & \\
EF-1a-qF & CCCCTTGGTCGTTTGCC & \\
EF-1a-qR & GCCTTGGTTGTCTTTCCGCTA & \\
\hline
\end{tabular}

Quantitative real-time PCR was used to analyze the level of I-FABP gene expression in golden pompano larvae. Gene specific primer pairs for the I-FABP gene (Table 1) were amplified in the LightCycler480 II system (Roche, Switzerland). EF-1a was used as the internal reference and amplified. The cycling conditions for I-FABP genes and EF-1a were as follows: $1 \mathrm{~min}$ at $95^{\circ} \mathrm{C}$, followed by 40 -cycles $95^{\circ} \mathrm{C}$ for $15 \mathrm{~s}$, and $60^{\circ} \mathrm{C}$ for $1 \mathrm{~min}$. Dissociation curves were used to guarantee that only one single PCR product was amplified in each gene reaction. For each test, three replicates were performed. The relative quantification ( $\mathrm{RQ}$ ) was calculated using the $\Delta \Delta \mathrm{CT}$ (comparative threshold cycle) method:

$\Delta \mathrm{CT}=\mathrm{CT}$ of target gene - CT of EF-1a,

$\Delta \Delta C T=\Delta C T$ of any sample $-\Delta C T$ of calibrator sample.

The efficiencies of the primers $(E)$ were $E$ I-FABP $=0.1001$. 
Sequences and phylogenic analysis. The I-FABP gene CDNA sequences were analyzed by BLAST at the National Center for Biotechnology Information (NCBI) (http://blast.ncbi.nlm.nih.gov/Blast.cgi). The complete ORF regions and amino acid sequences were deduced with ORF finder (http://www.ncbi.nlm.nih.gov/gorf/gorf.html). The molecular weight (Mw) and isoelectronic point ( $\mathrm{pI}$ ) of deduced amino acids were computed by the pI/Mw tool of ExPASy (http://web.expasy.org/compute_pi/). Protein domains were predicted using SMART (http://smart.embl-heidelberg.de/). Multiple sequence alignments of amino acids were performed by ClustalX 2.1. The phylogenetic tree was constructed by the neighbor-joining (NJ) method in MEGA 6.0, and the bootstrap values were replicated 1000 times to derive the confidence value for the analysis (Tamura et al., 2013). Pairwise deduced amino acid sequence identity and similarity matrices of the I-FABP family sequences from various species were performed using Matgat 2.02 (Campanella et al., 2003). The three-dimensional structures of golden pompano I-FABP were constructed through homology modelling (http://swissmodel.expasy.org/workspace/index.php).

Statistical analysis. The data were expressed as mean $\pm \mathrm{SD}$, and compared with oneway ANOVA (PASW Statistics 18.0, Chicago, SPSS Inc.). Tukey's test was used for multiple range comparisons with the level of significant difference set at $P<0.05$. All data were tested for normality, homogeneity and independence to satisfy the assumptions of ANOVA.

Results
Cloning and sequencing of golden pompano intestinal fatty acid binding protein (I-FABP) gene CDNA. The length of I-FABP gene CDNA sequence in the golden pompano (GenBank accession: MF034871) was 815 bp with an open reading frame (ORF) of $399 \mathrm{bp}$, which encoded one amino acid (aa) with a calculated molecular weight (Mw) of $15.24 \mathrm{kDa}$ and theoretical isoelectric point (pI) of 6.13. The bioinformatics analysis of the deduced polypeptide sequence revealed the signature sequence of a cytosolic fatty-acid binding protein (Fig. 1). The molecular modelling of golden pompano I-FABP is shown in Fig. 1. The golden pompano I-FABP sequence shared $67.94 \%$ identity with the rat intestinal fatty acid binding protein (PDB ID: 1ifc.1. A). There was one beta sheet, two helixes in $\mathrm{N}$-terminal amino acids and 10 anti-parallel beta sheets forming a hydrophobic pocket.

1 TGCAAACAGTTCTGCCATTCAAAAAGAATACAGAGTCATTTGGCATGGATTATTGGGCAT 60

61 GGCACAGTTCTTTCTATTCAAAACCACTGTGTTGCCCTATCAGCTGCAGTGCTAGATGTT 120

121 GCCATGAGAAAATTTGAGCTTTAAACGGCCACATCAGCATTCAGATAGATGACGAGATAA 180

181 GAGAGTGTGTGGTTTAAAAGGAGCGGCAGACTTTGAGTAAGACACTCCTTGCTGCAGAGT 240

241 TGTCCAGTTCAGCTCCCACCGCCACCatgaccttcaacggctcctggaaaat tgatcgca 300

$\begin{array}{lllllllllllllll}1 & \text { M } & \text { T } & \text { F } & \text { N } & \text { G } & \text { S } & \text { W } & \text { K } & \text { I } & \text { D } & \text { R } & \text { N } & 12\end{array}$

301 atgaaaactatgagaaattcatggaacaaatgggaat taacatggtgaagaggaagctgg 360

$\begin{array}{llllllllllllllllllllllllllllll}13 & \text { E } & \text { N } & \text { Y } & \text { E } & \text { K } & \text { F } & \text { M } & \text { E } & \text { Q } & \text { M } & \text { G } & \text { I } & \text { N } & \text { M } & \text { V } & \text { K } & \text { R } & \text { K } & \text { L } & \text { A } & 32\end{array}$

361 ctgctcacgacaacctcaagataaccattgaacagactggagacaagtttcatgtcaagg 420

$\begin{array}{lllllllllllllllllllllllllllllllll}33 & \text { A } & \text { H } & \text { D } & \text { N } & \text { L } & \text { K } & \text { I } & \text { T } & \text { I } & \text { E } & \text { Q } & \text { T } & \text { G } & \text { D } & \text { K } & \text { F } & \text { H } & \text { V } & \text { K } & \text { E } & 52\end{array}$

421 agagcagtaatttccgcactctggaaatagacttcaccctgggggtcacctttgagtaca 480

$\begin{array}{lllllllllllllllllllllll}53 & \text { S } & \text { S } & \text { N } & \text { F } & \text { R } & \text { T } & \text { L } & \text { E } & \text { I } & \text { D } & \text { F } & \text { T } & \text { L } & \text { G } & \text { V } & \text { T } & \text { F } & \text { E } & \text { Y } & \text { S } & 72\end{array}$

481 gccttgcagatggaacagaactaacaggctcatggaccattgagggagacatgatgaagg 540

$\begin{array}{llllllllllllllllllllll}73 & \mathrm{~L} & \mathrm{~A} & \mathrm{D} & \mathrm{G} & \mathrm{T} & \mathrm{E} & \mathrm{L} & \mathrm{T} & \mathrm{G} & \mathrm{S} & \text { W } & \mathrm{T} & \mathrm{I} & \mathrm{E} & \mathrm{G} & \mathrm{D} & \mathrm{M} & \mathrm{M} & \mathrm{K} & \mathrm{G} & 92\end{array}$

541 gggtttcatcagaaaggacaatggaaagcagctgacaacaaccagaatcattcaaggag 600

$\begin{array}{llllllllllllllllllllll}93 & \mathrm{~V} & \mathrm{~F} & \mathrm{I} & \mathrm{R} & \mathrm{K} & \mathrm{D} & \mathrm{N} & \mathrm{G} & \mathrm{K} & \mathrm{Q} & \mathrm{L} & \mathrm{T} & \mathrm{T} & \mathrm{T} & \mathrm{R} & \mathrm{I} & \mathrm{I} & \mathrm{Q} & \mathrm{G} & \mathrm{D} & 112\end{array}$

601 atgaactcgtacagagctacaactatgatggtgtggacgcaaagaggattttcaagaggg 660

$\begin{array}{llllllllllllllllllllllllllllllllll}113 & \mathrm{E} & \mathrm{L} & \mathrm{V} & \mathrm{Q} & \mathrm{S} & \mathrm{Y} & \mathrm{N} & \mathrm{Y} & \mathrm{D} & \mathrm{G} & \mathrm{V} & \mathrm{D} & \mathrm{A} & \mathrm{K} & \mathrm{R} & \mathrm{I} & \mathrm{F} & \mathrm{K} & \mathrm{R} & \mathrm{G} & 132\end{array}$

661 gttagACCACAAATGTTTGATTACAGGATTACATACAGTATTGTGATAAATCATTGACTT 720

$*$

721 ATACCTAATAACCTGTGAAAAGTGCACTTCTTGTAATGCCATATATTTGAATTGCATTGG 780

781 ATTTTGATACTTGCAGTAATAAAGTGATACTGTAA 


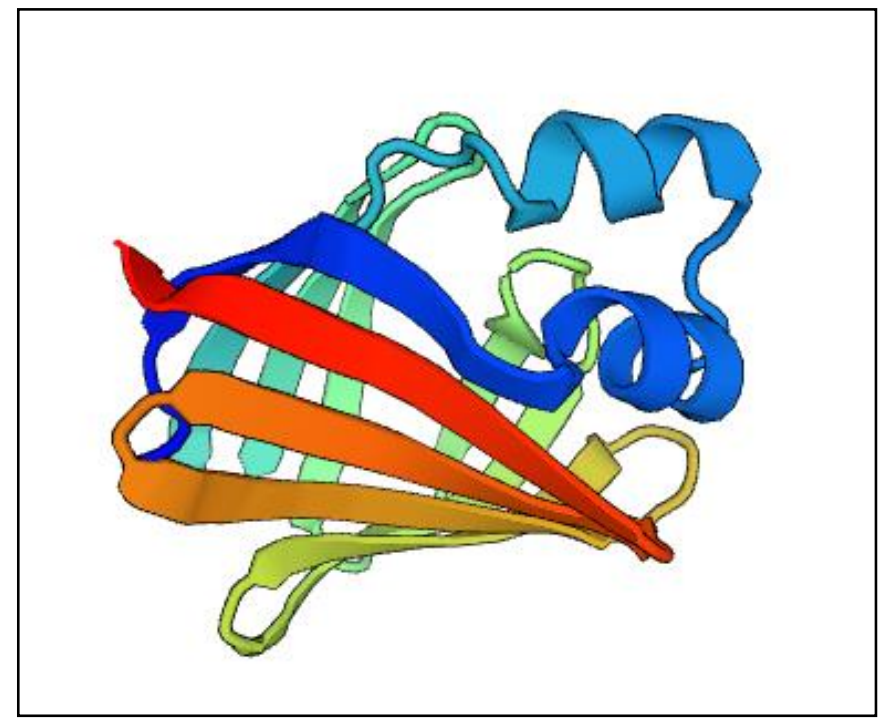

Fig. 1 Nucleotide sequence and deduced amino acids of the intestinal fatty acid binding protein (I-FABP) gene and predicted tertiary structure of I-FABP from golden pompano Trachinotus ovatus (Linnaeus 1758) Cytosolic fatty-acid binding proteins signature was underlined.

Multiple sequence alignments and phylogenetic analysis. Multiple sequence alignment of the deduced amino acid sequences of I-FABP genes with some known I-FABP family amino acid sequences from various species is shown in Table 2 . The predicted amino acid sequence of I-FABP genes from golden pompano showed high similarity and identity with Japanese seabass Lateolabrax japonicus (97\% and 87.9\%, AOW69620.1) and large yellow croaker Larimichthys crocea (93.2\% and $85 \%$, ALP43793.1), but different similarity (82.6-93.9\%) and identity (65.2$82.6 \%$ ) with other species (Table 2). The phylogenetic tree of hedgehog genes (Ma et el., 2017) comprised two main clusters, i.e., the fish clusters, and the bird and mammal clusters (Fig. 2). The deduced I-FABP amino acid sequences of eight fishes and three other vertebrates contained the cytosolic fatty-acid binding proteins signature, and all showed high identity and similarity (Fig.3).

Table 2. Identity and similarity of I-FABP between golden pompano and other species homologue.

\begin{tabular}{lllll}
\hline Species & Accession NO. & AA & $\begin{array}{l}\text { Similarity } \\
(\%)\end{array}$ & $\begin{array}{l}\text { Identity } \\
\text { (\%) }\end{array}$ \\
\hline Trachinotus ovatus & Present study & 132 & & \\
Lateolabrax japonicus & AOW69620.1 & 132 & 97 & 87.9 \\
Larimichthys crocea & ALP43793.1 & 132 & 93.2 & 85 \\
Oncorhynchus kisutch & XP_020352621.1 & 132 & 93.9 & 81.1 \\
Danio rerio & AAF00925.1 & 132 & 90.2 & 82.6 \\
Cyprinus carpio & ADF28554.1 & 132 & 90.2 & 80.3 \\
Salmo salar & ACI66628.1 & 132 & 92.4 & 79.5 \\
Ictalurus punctatus & NP_001187833.1 & 132 & 89.4 & 76.5 \\
Columba livia & NP_001269737.1 & 132 & 86.4 & 75.8 \\
Columba livia & NP_000125.2 & 132 & 82.6 & 65.2 \\
Mus musculus & NP_032006.1 & 132 & 82.6 & 65.9 \\
Rattus norvegicus & NP_032006.1 & 132 & 83.3 & 67.4 \\
\hline
\end{tabular}

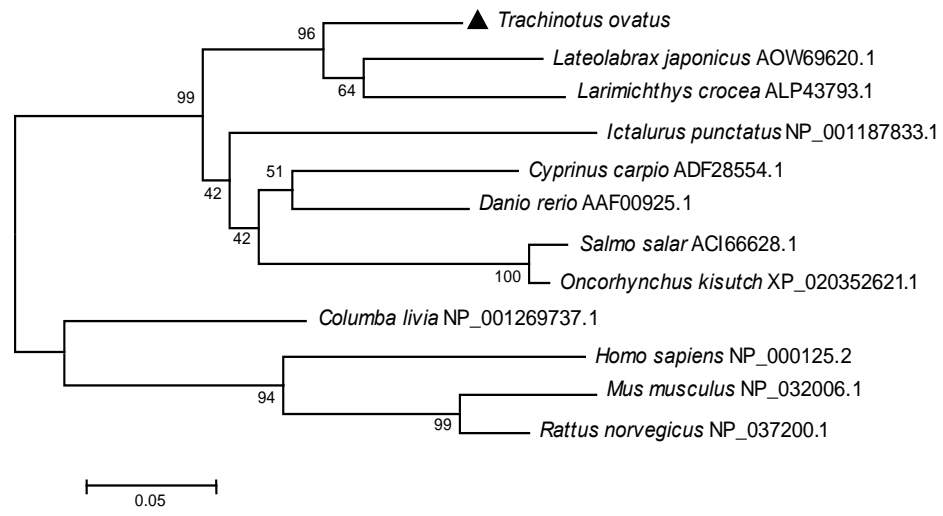

Fig 2. Phylogenetic tree of intestinal fatty acid binding protein. The numbers represent the frequencies with which the tree topology presented here were replicated after 1000 bootstrap iterations. 
Trachinotus ovatus

MTFNGSWKIDRNENYEKFMEQMGINMVKRKLAAHDNLKITIEQTGDKFHVKESSNFRTLE 60 Lateolabrax japonicus

MTFDGNWKIDRSENYEKFMEKMGINMVKRKLAAHDNLKITIEQTGDKFQVKESSKFRTLE 60 Larimichthys crocea MTFNGTWKVDRNDNYEKFMEKMGINMVKRKLASHDGLKITIEQNGDKFHVKESSNFRTLE 60 Oncorhynchus kisutch

MTYNGTWKVDRSENYEKFMEQMGVNMVKRKLAAHDNLKITLEQTGDKFVVKEASSFRTLD 60 Danio rerio

MTFNGTWKVDRNENYEKFMEQMGVMMVKRKLAAHDNLKITLEQTGDKFNVKEVSTFRTLE 60 Cyprinus carpio

MTFNGTWKVDRNENYEKFMEQMGINMVKRKLASHDNLKITLEQTGDQFHVKESSTFRSLE 60 Salmo salar

MTYNGTWKVDRSENYEKFVEQMGVNMVKRKLAAHDNLKITLEQTGDKFVVKEASSFRTLD 60 Ictalurus punctatus

MAFNGTWKVDRSENYDKFMEQMGINLVKRKLAAHDNLKITLEQNEDTFHVKEVSTFRTLE 60 Columba livia

MAFNGTWKIDRNENYEKFMEAMGINVMKRKLGAHDNLKITIQQDGNKFTVKESSNFRTID 60 Homo sapiens

MAFDSTWKVDRSENYDKFMEKMGVIIVKRKLAAHDNLKLTITQEGNKFTVKESSTFRNIE 60 Mus musculus

MAFDGTWKVDRNENYEKFMEKMGINVMKRKLGAHDNLKLTITQDGNKFTVKESSNFRNID 60 Rattus norvegicus

MAFDGTWKVDRNENYEKFVEKMGINVVKRKLGAHDNLKLTITDEGNKFTVKESSNFRNID 60 Clustal Consensus $*::$ : . **:**. :**:**** **:*: :****. :**. **:*

*: : *****.**. : : 46

Trachinotus ovatus

IDFTLGVTFEYSLADGTELTGSWT IEGDMMKGVFIRKDNGKQLTTTRIIQGDELVQSYNY 120 Lateolabrax japonicus

IDFTLGVTFEYSLADGTELSGSWNMEGDMLKGIFNRKDNGKQLVTTRIVQGDELIQSYNY 120 Larimichthys crocea

IDFTLGVTFEYSLADGTELSGSWAMEGDMMKGTFNRKDNGKLLTTTRIVQNDELIQSYNY 120 Oncorhynchus kisutch

LEFTLGVTFEVALADGTMLSGSWGMEGDMMKGTFTRKDNGKVLTTTRAIVGEELVQSYSY 120 Danio rerio

INFTLGVTFDYSLADGTELTGSWVIEGDTLKGTFTRKDNGKVLTTVRTIVNGELVQSYSY 120 Cyprinus carpio

INFTLGVNFDYSQADGTELTGSWVMEGDMLKGTFTRKDNGKSLITTRKIVGEELVQIVTY 120 Salmo salar

MEFTLGVTFEYALADGTMISGSWGMEGDMMKGTFTRKDNGKVLKTTRAIVGEELVQSYSY 120 Ictalurus punctatus

LDFKLGVTFQYSLADGTELSGSWVMEGDVLKGSFIRKDNGKTLTTIRQIVGDELVQSYSY 120
Fig 3. Multiple sequence alignment of the deduced amino acid sequence of I-FABP with other known homologous I-FABP amino acid sequence. 
Ontogenetic expression of I-FABP gene. The expression level of I-FABP genes in golden pompano larvae was low at hatching, but slowly increased with the increase of fish age from $0 \mathrm{DPH}$ to $5 \mathrm{DPH}$ (Fig. 4). The expression of I-FABP genes reached the highest level on $12 \mathrm{DPH}(\mathrm{P}<0.05)$, and remained at the similar level until the end of the experiment on $18 \mathrm{DPH}$.

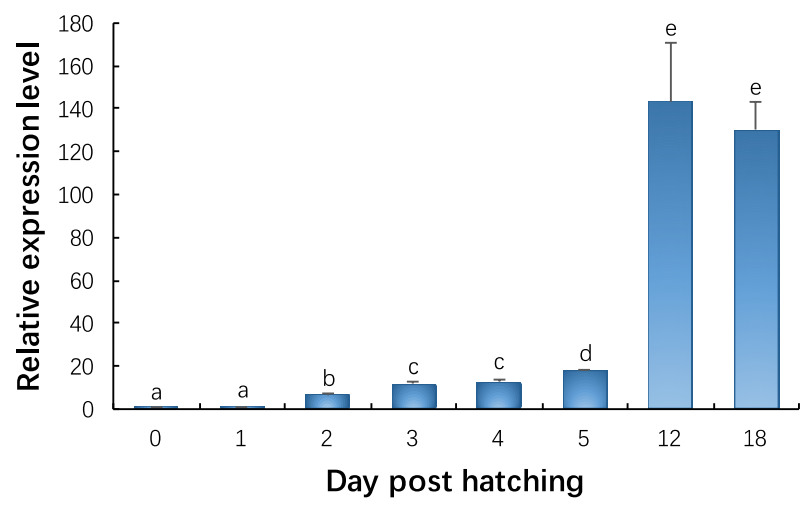

Fig. 4. Ontogenetic expression of the I-FABP gene in golden pompano larvae. Data with different letters were significantly different $(P<0.05)$.

Tissue expression of I-FABP gene in golden pompano. On $18 \mathrm{DPH}$, the highest expression of I-FABP gene in golden pompano was observed in the intestine $(P<0.05$, Fig. 5), followed by in the eye. The expressions of I-FABP genes in the brain, gills, headkidney, spleen, and stomach were significantly lower than the expression observed in the liver, muscle, and heart $(P<0.05)$. The expression of I-FABP gene in the muscle and heart was not significantly different $(P>0.05)$.

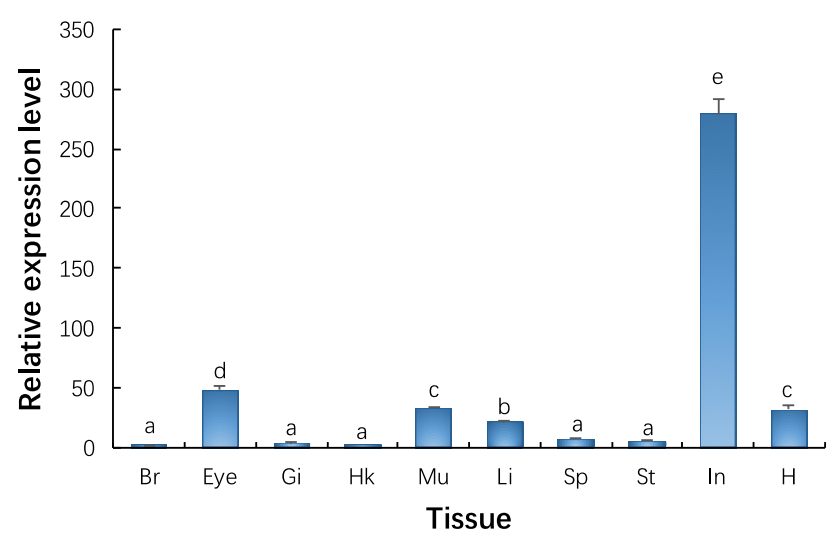

Fig. 5 Tissue expression of I-FABP gene in golden pompano larvae. Data with different letters were significantly different $(P<0.05)$. Abbreviations: $B r$, Brain; Gi, Gill; Hk, Head-kidney; Mu, Muscle; $\mathrm{Li}$, Liver; Sp, Spleen; St, Stomach; In, Intestine; $\mathrm{H}$, Heart; K, Kidney.

Response of I-FABP genes to water temperature and nutrition manipulation. On 12 $\mathrm{DPH}$, the expression of I-FABP gene was not significantly affected by rearing temperature $\left(\mathrm{P}>0.05\right.$, Fig. 6). On $18 \mathrm{DPH}$, the highest expression of I-FABP gene was found at $29^{\circ} \mathrm{C}$ $(P<0.05)$, but the expression of I-FABP gene was not significantly different between fish cultured at $23^{\circ} \mathrm{C}$ and $26^{\circ} \mathrm{C}(P>0.05)$. The expression of I-FABP gene was significantly 
affected by nutrition manipulation ( $P<0.05$, Fig. 7). The highest expression of I-FABP gene was observed in the non-enriched group, and lowest expression of I-FABP gene was found in the Nannochloropsis enriched group.

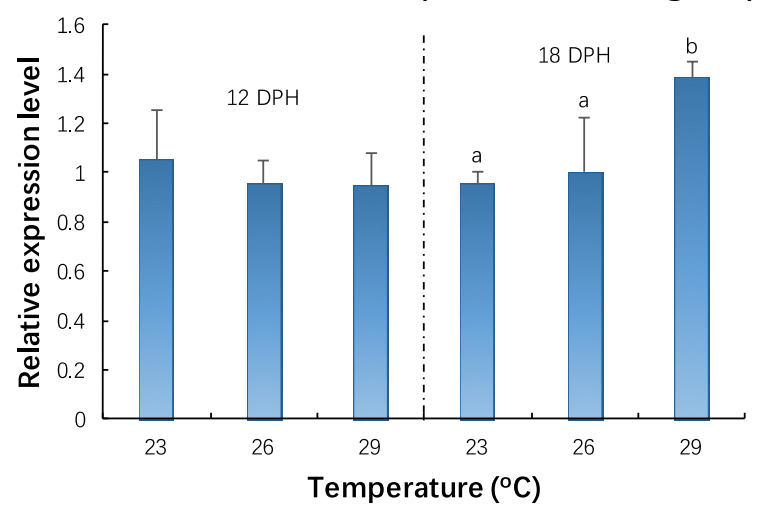

Fig. 6 Response of I-FABP gene to water temperature in golden pompano larvae. Data with different letters were significantly different $(P<0.05)$.

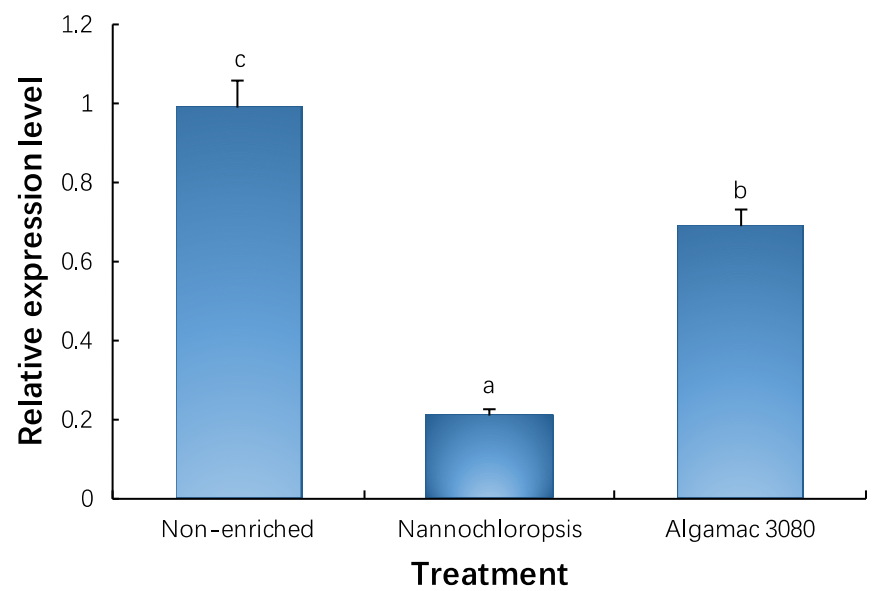

Fig. 7 Response of I-FABP gene to nutrition manipulation in golden pompano larvae. Data with different letters were significantly different $(P<0.05)$.

\section{Discussion}

In the present study, the I-FABP gene in golden pompano larvae was successfully isolated and identified. Similar to the FABP obtained from other species, such a unique structure in I-FABP allows it to actively participate in transporting fatty acids and other lipid soluble substances within cells (Andre et al., 2000; Hsu and Storch, 1996; Venold et al., 2012).

Expression of the I-FABP gene during ontogenetic development. In the present study, the expression level of I-FABP gene in fish remained at a low level at hatching, but slowly increased before $5 \mathrm{DPH}$. On $12 \mathrm{DPH}$, the expression of I-FABP sharply increased and reached the highest level. This expression pattern is consistent with the development of the digestive tract of golden pompano larvae, as the digestive system of golden pompano is primitive at hatching, and a functional digestive system appeared around $15 \mathrm{DPH}$ (Ma et al., 2014). The expression of I-FABP gene during embryogenesis and early development has been reported in zebrafish through in situ hybridization (Andre et al., 2000; Sharma et al., 2004). To the best of our knowledge, there was no report on the expression level of I-FABP gene during early development of fish larvae. In terrestrial species such as pigeon, chickens, and turkeys, the expression of I-FABP gene significantly increases after hatching (Ding and Lilburn, 2002; Katongole and March, 1980; Xie et al., 2013), while the expression level of I-FABP gene in mice rises rapidly on day 17 during embryonic development (Green et al., 1992). Furthermore, the increase of I-FABP over time after hatching may be correlated with the uptake of dietary fatty acids 
after the formation of a functional digestive tract at the late developmental stage of larval golden pompano.

Expression of I-FABP gene in different tissues. Although FABPs were originally named from the tissue where they were discovered, they are widely expressed proteins, and their expressions are species dependent in animal tissues. For instance, the expression of I-FABP gene is only observed in the intestinal tissue of humans (Sweetser et al., 1987), while the expression of I-FABP gene in zebrafish (Danio rerio) can be detected in intestine and brain (Sharma et al., 2004). In Atlantic salmon (Salmo salar), the expression of I-FABP gene can be observed in various tissues such as stomach, pyloric caeca, intestine, spleen, muscle, and brain (Venold et al., 2013). In the present study, the highest expression of I-FABP gene was observed in intestine, followed by the eye, and then in the muscle and heart. Furthermore, the expression of I-FABP gene was also observed in the stomach of larval golden pompano, but the expression level was lower than that reported in Atlantic salmon (Venold et al., 2013). In the present study, the expression of I-FABP gene in the eye of larval golden pompano was not previously reported in fish, and the functional expression of this gene in the eye may be related to vision development but this claim warrants further investigation.

Response of I-FABP gene to water temperature. Temperature is an important environmental factor in larval fish development, and can significantly affect fish feeding behavior and metabolism (Blaxter, 1992; Ma, 2014). Early studies have demonstrated that environmental temperature can regulate fatty acid metabolism and composition in fish (Farkas et al., 1980; Kemp and Smith, 1970; Skalli et al., 2006). As an important fatty acid binding protein in fish, I-FABP plays an essential role in fatty acid absorption (Storch and Thumser, 2010). However, it is unclear if temperature can affect the expression of I-FABP gene during the early development of fish larvae. In this study, the expression of I-FABP gene was not significantly affected by water temperature on 12 $\mathrm{DPH}$, but was significantly affected by temperature on $18 \mathrm{DPH}$. Such difference may reflect the developmental stage of the digestive system in larval golden pompano as the functional stomach did not appear until $18 \mathrm{DPH}$.

Response of I-FABP gene to nutrition enhancement. Fatty acid binding proteins can affect gene regulation, leading to up-regulation of lipid related genes via activation of the peroxisome proliferating receptor (Lawrence et al., 2000; Tan et al., 2002). In Atlantic salmon, the expression level of I-FABP genes reduced when fish were fed with soybean meal (Venold et al., 2013). The reduction of the expression level of I-FABP gene is related to inflammation in the distal intestine of Atlantic salmon due to inclusion of soybean meal in the diet and is a sign of functional loss for the ability to bind dietary fatty acids (Venold et al., 2013). In the present study, the expression of I-FABP gene was significantly affected by nutrition enhancement. The highest expression of I-FABP gene was observed in the non-enriched feeding group, and the lowest expression was found in the Nannochloropsis enriched group. This expression pattern is inversely proportional to the total amount of polyunsaturated fatty acids in the diet. In the experimental diet, the Nannochloropsis enriched diet contained a higher content of polyunsaturated fatty acids than the non-enriched diet (Yang et al., 2015). This may suggest that the total poly unsaturated fatty acid in the diet has a negative effect on the expression of I-FABP gene in golden pompano larvae. However, there is no direct evidence to prove it, and this may need further investigation.

In summary, the I-FABP CDNA was cloned and analyzed in golden pompano larvae in this study. The expression of I-FABP gene in golden pompano larvae was significantly affected by water temperature and fatty acid content in the feed when the functional stomach formed on $18 \mathrm{DPH}$. The time dependent expression of I-FABP gene in fish larvae is important to understand the ontogenetic development and growth of fish larvae in early life. The monitoring of I-FABP gene expression in golden pompano larvae may serve as a useful indicator in the field and on fish farms, leading to a rapid assessment of environmental conditions and nutrition impact on fish development. 


\section{Acknowledgements}

This project was supported by National Natural Science Foundation of China (31502186), Pearl River S\&T Nova Program of Guangzhou (201610010166), and Ministry of Human Resources and Social Security of China (2016 High-level Overseas Researcher Come Back to Work Funds). Dr. Mingjun Fu provided technical supports on gene clone and analysis.

\section{References}

Alvite, G., Canclini, L., Corvo, I. and Esteves, A., 2008. Two novel Mesocestoides vogae fatty acid binding proteins - functional and evolutionary implications. FEBS Journal. 16, 107-116.

Andre, M., Ando, S., Ballagny, C., Durliat, M., Poupard, G., Briancon, C. and Babin, P.J., 2000. Intestinal fatty acid binding protein gene expression reveals the cephalocaudal patterning during zebrafish gut morphogenesis. The Int J Devel Biol. 44, 249-252.

Banaszak, L., Winter, N., Xu, Z., Bernlohr, D.A., Cowan, S. and Alwyn Jones, T., 1994. Lipid-binding proteins: a family of fatty acid and retinoid transport proteins, Shumaker, V. (Ed.), Advances in Protein Chemistry,. Academic Press, San Diego, pp. 89151.

Besnard, P., Niot, I., Poirier, H., Clement, L. and Bernard, A., 2002. New insights into the fatty acid-binding protein (FABP) family in the small intesine. Molecular and Cellular Biochemistry. 239, 139-147.

Blaxter, J.H.S., 1992. The effect of temperature on larval fishes. Neth. J. Zool. 42, 336357.

Borchers, T., Unterberg, C., Rudel, H., Robenek, H. and Spener, F., 1989. Fatty acid-binding proteins. 10. Subcellular distribution of cardiac fatty acid-binding protein in bovine heart muscle and quantitation with an enzyme-linked immunosorbent assay. Biochimica et Biophysica Acta. 1002, 54-61.

Campanella, J.J., Bitincka, L. and Smalley, J., 2003. MatGAT: an application that generates similarity/identity matrices using protein or DNA sequences. BMC Bioinformatics. 4, 29.

Chalmers, A.D., Slack, J.M. and Beck, C.W., 2000. Regional gene expression in the epithelia of the Xenopus tadpole gut. Mechanisms of Development. 96, 125-128.

Chen, X. and Shi, Z., 2009. Sequence analysis of the full-length CDNA and protein structure homology modeling of FABP2 from Paralichthys olivaceus. Bioinformatics and Biology Insights 3, 29-35.

Ding, S.T. and Lilburn, M.S., 2002. The ontogeny of fatty acid-binding protein in turkey (Meleagridis gallopavo) intestine and yolk sac membrane during embryonic and early posthatch development. Poultry Science. 81, 1065-1070.

Farkas, T., Csengeri, I., Majoros, F. and Olah, J., 1980. Metabolism of fatty acids in fish: III. Combined effect of environmental temperature and diet on formation and deposition of fatty acids in the carp, Cyprinus carpio Linnaeus 1758. Aquaculture. 30, 2940.

Green, R.P., Cohn, S.M., Sacchettini, J.M., Jackson, K.E. and Gordon, J.I., 1992. The mouse intestinal fatty acid binding protein gene: nucleotide Sequence, pattern of developmental and regional expression, and proposed structure of its protein product. Dna and Cell Biology. 11, 31-41.

Her, G.M., Chiang, C. and Wu, J., 2004. Zebrafish intestinal fatty acid binding protein (I-FABP) gene promoter drives gut-specific expression in stable transgenic fish. Genesis. 38, 26-31.

Hsu, K.T. and Storch, J., 1996. Fatty acid transfer from liver and intestinal fatty acidbinding proteins to membranes occurs by different mechanisms. J Biol Chem. 271, 13317-13323.

Kanda, T., Iseki, S., Hitomi, M., Kimura, H., Odani, S., Kondo, H., Matsubara, Y., Muto, T. and Ono, T., 1989. Purification and characterization of a fatty-acid-binding protein from the gastric mucosa of rats. Possible identity with heart fatty-acid-binding protein and its parietal cell localization. European J Biochem. 185, 27-33. 
Katongole, J.B.D. and March, B.E., 1980. Fat utilization in relation to intestinal fatty acid binding protein and bible salts in chicks of different ages and different genetic sources. Poultry Science. 59, 819-827.

Kemp, P. and Smith, M.W., 1970. Effect of temperature acclimatization on the fatty acid composition of goldfish intestinal lipids. Biochemical Journal. 117, 9-15.

Hongyan Kou, Shuying Xu, An-Li Wang*, 2015. Effect of Replacement of Fish Meal with Canola Meal in Diets on the Growth, Digestive Enzyme Activities and Amino Acids of Ovate Pompano, Trachinotus ovatus, 10 pages. Isr. J. Aquacult.-Bamidgeh, IJA_67.2015.1144.

Lawrence, J.W., Kroll, D.J. and Eacho, P.I., 2000. Ligand-dependent interaction of hepatic fatty acid-binding protein with the nucleus. J Lipid Res. 41, 1390-1401.

Likic, V.A. and Prendergast, F.G., 1999. Structure and dynamics of the fatty acid binding cavity in apo rat intestinal fatty acid binding protein. Protein Science. 8, 16491657.

Lowe, J.B., Sacchettini, J.C., Laposata, M., McQuillan, J.J. and Gordon, J.I., 1987. Expression of rat intestinal fatty acid-binding protein in Escherichia coli. Purification and comparison of ligand binding characteristics with that of Escherichia coli-derived rat liver fatty acid-binding protein. J Biol Chem. 262, 5931-5937.

Ma Z., Fu M., Hu J., Yang R., Wei C., Qin J.G., Yu G., 2017. Molecular cloning of Indian hedgehog gene and its expression in golden pompano Trachinotus ovatus (Linnaeus 1758) larvae at different water temperatures, 13 pages. Isr. J. Aquacult.Bamidgeh, IJA_69.2017.1392

Ma, Z., 2014. Food ingestion, prey selectivity, feeding incidence, and performance of yellowtail kingfish Seriola lalandi larvae under constant and varying temperatures. Aquacult Int. 22, 1317-1330.

Ma, Z., Guo, H., Zheng, P., Wang, L., Jiang, S., Qin, J.G. and Zhang, D., 2014. Ontogenetic development of digestive functionality in golden pompano Trachinotus ovatus (Linnaeus 1758). Fish Physiol Biochem. 40, 1157-1167.

Ma, Z., Hu, J., Liu, Y., Yang, R., Qin, J.G. and Sun, D., 2016a. Molecular cloning and response to water temperature and nutrient manipulation of insulin-like growth factor (IGF) genes in golden pompano Trachinotus ovatus (Linnaeus 1758) larvae. Isr. J. Aquacult.-Bamidgeh, IJA_68.2016.1336, 14 pages.

Ma, Z., Zheng, P., Guo, H., Zhang, N., Jiang, S., Zhang, D. and Qin, J.G., 2016b. Jaw malfromation of hatchery reared golden pompano Trachinotus ovatus (Linnaeus 1758) larvae. Aquacult Res. 47, 1141-1149.

Overland, M., Sorensen, M., Storebakken, T., Penn, M., Krogdahl, A. and Skrede, A., 2009. Pea protein concentrate substituting fish meal or soybean meal in diets for Atlantic salmon (Salmo salar) - effect on growth performance, nutrient digestibility, carcass composition, gut health, and physical feed quality. Aquaculture. 288, 305-311.

Pelsers, M.M.A.L., Hermens, W.T. and Glatz, J.F.C., 2005. Fatty acid-binding proteins as plasma markers of tissue injury. Clinica Chimica Acta. 352, 15-35.

Pierce, M., Wang, Y., Denovan-Wright, E.M. and Wright, J.M., 2000. Nucleotide sequence of a cDNA done coding for an intestinal-type fatty acid binding protein and its tissue-specific expression in zebrafish (Danio rerio). Biochimica et Biophysica Acta. 1490, 175-183.

Schroyen, M., Stinchens, A., Verhelst, R., Geens, M., Cox, E., Niewold, T. and Buys, N., 2012. Susceptibility of piglets to enterotoxigenic Escherichia coli is not related to the expression of MUC13 and MUC20. Animal Genetics. 43, 324-327.

Sharma, M.K., Denovan-Wright, E.M., Degrave, A., Thisse, C. and Wright, J.M., 2004. Sequence, linkage mapping and early developmental expression of the intenstinaltype fatty acid-binding protein gene (fabp2) from zebrafish (Danio rerio). Comp Biochem Physiol B. 138, 391-398.

Simula, M.P., Cannizzaro, R., Canzonieri, V., Pavan, A., Maiero, S., Toffoli, G. and De $\mathbf{R e}, \mathbf{V} ., 2010$. PPAR signaling pathway and cancer-related proteins are involved in celiac disease-associated tissue damage. Mol Med. 16, 199-209. 
Skalli, A., Robin, J.H., Le Bayon, N., Le Delliou, H. and Person-Le Ruyet, J., 2006. Impact of essential fatty acid deficiency and temperature on tissues' fatty acid composition of European sea bass (Dicentrarchus labrax). Aquaculture. 255, 223-232.

Sonnino, R., Ereso, G., Arcuni, J. and Franson, R., 2000. Human intestinal fatty acid binding protein in peritoneal fluid is a marker of intestinal ischemia. Transplantation Proceedings. 32, 1280.

Storch, J. and McDermott, L., 2009. Structural and functional analysis of fatty acidbinding proteins. J Lipid Res. 50, S126-131.

Storch, J. and Thumser, A.E., 2010. Tissue-specific functions in the fatty acid-binding protein family. J Biol Chem. 285, 32679-32683.

Sweetser, D.A., Birkenmeir, E.H., Klisak, I.J., Zollman, S., Sparkes, R.S., Mohandas, T., Lusis, A.J. and Gordon, J.I., 1987. The human and rodent intestinal fatty acid binding protein genes. A comparative analusos pf their structure, expression, and linkage relationships. The Journal of Biological Chemistry. 262, 16060-16071.

Tamura, K., Stecher, G., Peterson, D., Filipski, A. and Kumar, S., 2013. MEGA6: Molecular Evolutionary Genetics Analysis version 6.0. Mol Biol Evol. 30, 2725-2729.

Tan, N.S., Shaw, N.S., Vinckenbosch, N., Liu, P., Yasmin, R., Desvergne, B., Wahli, W. and Noy, N., 2002. Selective cooperation between fatty acid binding proteins and peroxisome proliferator-activated receptors in regulating transcription. Mol Cell Biol. 22, 5114-5127.

Veerkamp, J.H., Peeters, R.A. and Maatman, R.G., 1991. Structural and functional features of different types of cytoplasmic fatty acid-binding proteins. Biochimica et Biophysica Acta. 1081, 1-24.

Veerkamp, J.H., Van Kuppevelt, T.H.S.M., Maatman, R.G.H., J., and Prinsen, C.F.M., 1993. Prinsen, structural and functional aspects of cytosolic fatty-acid-binding proteins. Prostaglandins, Leukotrienes and Essential Fatty Acids. 49, 887-906.

Venold, F.F., Penn, M.H., Krogdahl, A. and Overturf, K., 2012. Severity of soybean meal induced distal intestinal inflammation, enterocyte proliferation rate, and fatty acid binding protein (Fabp2) level differ between strains of rainbow trout (Oncorhynchus mykiss). Aquaculture. 364-365.

Venold, F.F., Penn, M.H., Thorsen, J., Gu, J., Kortner, T.M., Krogdahl, A. and Bakke, A.M., 2013. Intestinal fatty acid binding protein (fabp2) in Atlantic salmon (Salmo salar): Localization and alteration of expression during development of diet induced enteritis. Comp Biochem Physiol A. 164, 229-240.

Xie, P., Liu, L., Wang, C. and Zou, X., 2013. Molecular cloning, characterization, and mRNA expression of intestinal fatty acid binding protein (I-FABP) in Columba livia. $J$ Poultry Sci. 50, 9-19.

Yamamoto, T., Suzuki, N., Furuita, H., Sugita, T., Tanaka, N. and Goto, T., 2007. Supplemental effect of bible salts to soybean meal-based diet on growth and feed utilization of rainbow trout Oncorhynchus mykiss. Fish Sci. 73.

Yang, Q., Zheng, P., Ma, Z., Li, T., Jiang, S. and Qin, J.G., 2015. Molecular cloning and expression analysis of the retinoid $X$ receptor (RXR) gene in golden pompano Trachinotus ovatus fed Artemia nauplii with different enrichements. Fish Physiol Biochem. DOI: $10.1007 / \mathrm{s} 10695-015-0098-x$.

Zheng, K., Yue, H., Zheng, P. and Ma, Z., 2016. Skeletal ontogeny and deformities in commercially cultured marine fish larvae. J Fish Sci China. 23, 250-261. 